\title{
Constructed floating treatment wetlands: can they improve water quality in a northern USA climate?
}

\begin{abstract}
Constructed floating treatment wetlands (FTWs) are a best management practice (BMP) applied in aquatic environments to improve water quality by mitigating nutrient pollution. We evaluated the efficacy of FTWs in Minnesota, USA as a tool for the removal of excess nutrients in surface water to enhance water quality. We began with a 2015 outdoor mesocosm study to quantify the removal efficiency of total phosphorus (TP), orthophosphate-P $\left(\mathrm{PO}_{4}-\mathrm{P}\right)$, nitrate- $\mathrm{N}$, and ammonia-N. The FTWs were each planted with wetland plants Juncus effusus, Eleocharis acicularis, and Glyceria canadensis. A paired controlled TP budget was prepared to identify mesocosm sources and sinks. Mesocosm FTWs showed higher $\mathrm{PO}_{4}$-P reduction efficiencies than the control mesocosms. Mesocosms with FTWs had significantly lower $\mathrm{pH}$ and dissolved oxygen (DO) concentrations. Water quality measurements were made along with qualitative observations, such as durability, at two different field scales where FTWs were installed in a pond and lake in 2016. Field deployed FTWs showed measurable changes in several water quality parameters over the study period. Statistically significant reductions were observed in $\mathrm{PO}_{4}-\mathrm{P}, \mathrm{DO}$, and $\mathrm{pH}$ for the pond site but not at the lake site. Though positive results were observed, factors other than FTWs may better explain the field deployed FTW results. Overall, the high FTW spatial coverage $(15 \%)$ in the mesocosms showed clear $\mathrm{PO}_{4}-\mathrm{P}$ removal, whereas low FTW spatial coverage $(<1 \%)$ of the field scale surface water was likely the most limiting factor to achieving optimal water quality at the study sites and rather than individual FTW performance.
\end{abstract}

Keywords: floating treatment wetland island, nutrients, lake eutrophication
Volume 5 Issue 6 - 202I

\author{
Mattias Oddsson,' Emily Deering, ${ }^{2}$ Ren \\ Ortega, ${ }^{3}$ Joe Magner' \\ 'Department of Bioproducts and Biosystems Engineering (BBE), \\ University of Minnesota, USA \\ ${ }^{2}$ Formerly with BBE, now at SRF Consulting, USA \\ ${ }^{3}$ Formerly with BBE, now at Case Western Reserve, USA
}

Correspondence: Joe Magner, Bioproducts \& Biosystems Engineering, University of Minnesota, St. Paul, Minnesota, USA, Email jmagner@umn.edu

Received: December 05, 2021 | Published: December 24, 2021

\section{Introduction}

Constructed floating treatment wetlands (FTWs) are developed to mimic natural floating bogs. FTWs are also referred to in literature as constructed floating islands, floating beds, or suds, and are considered a water quality improvement best management practice (BMP). FTWs are made of recycled plastics. Marine-grade foam is inserted into the porous, plastic media to help the BMP float. Anchoring ensures the FTW remains in place in both lentic and lotic waters. Holes are drilled within the islands to provide areas to plant macrophytes. ${ }^{1}$ Plant roots are designed to grow through the FTW and into the water column. Biofilms grow on the macrophyte roots and the FTW structure ${ }^{2-3}$ (Figures 1a and 1b). The FTW has wildlife habitat benefits, but is primarily used to control eutrophication through the reduction of nutrient pollutants such as phosphorus, and particularly ortho-phosphate $\left(\mathrm{PO}_{4}-\mathrm{P}\right)$, nitrate- $\mathrm{N}\left(\mathrm{NO}_{3}-\mathrm{N}\right)$, and ammonia-N which drive suspended fine algae particles in warm polluted water. ${ }^{3-4}$ Elevated nutrient concentrations, which can be caused by wastewater, agricultural activity or runoff from urban impervious surfaces can drive algal blooms, which reduce the dissolved oxygen (DO) available to aquatic life. Given the right conditions, hypoxic 'dead zones' can occur in selected surface waters for a given season and or year. ${ }^{5-6}$ The ideal solution is naturally to address the source of the pollution, but this can in some cases be prohibitively difficult. Nonpoint sources of pollution such as agricultural runoff, which can be distributed over a wide area and lack a single point of origin, contributed approximately $82-84 \%$ of nitrogen and phosphorus that flowed into in North America waters. ${ }^{6}$ There are some existing methods and BMPs for controlling nonpoint source nutrient pollution, such as nutrient management, conservation tillage, and filter strips, ${ }^{1}$ nevertheless, nutrients can still find pathways of entry into surface water. The difficulty inherent in regulating nonpoint sources of pollution means that an in-situ method that directly treats surface water is a desirable option for controlling nutrient pollution.

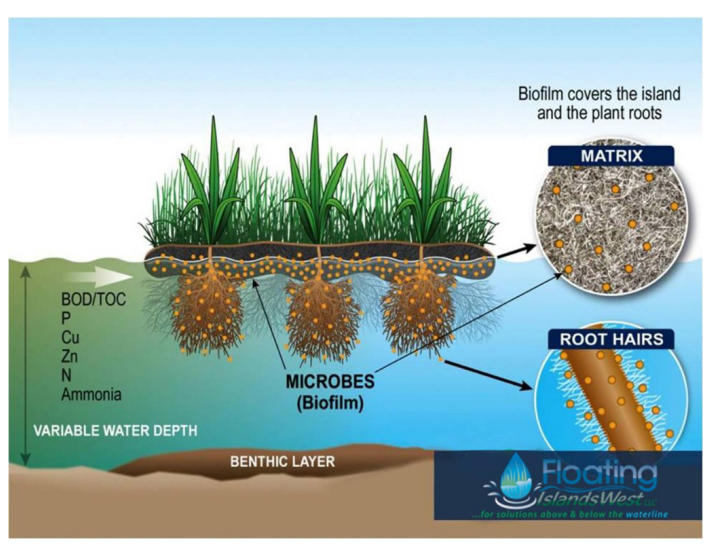

Figure I A Cut-away diagram of the components of a FTW (diagram created by Floating Islands West, 2017). ${ }^{13}$

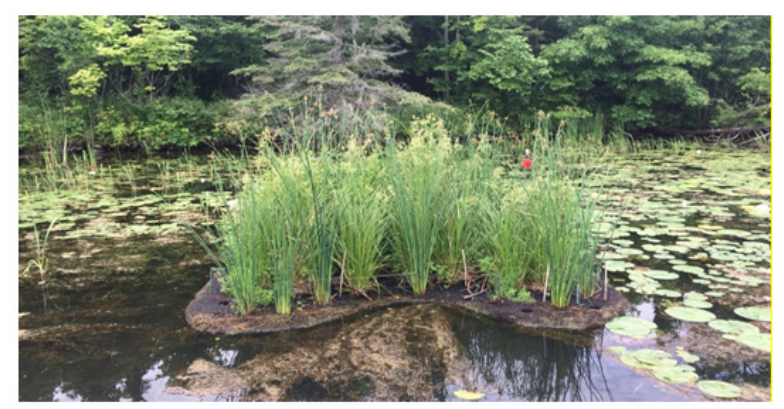

Figure IB A floating treatment wetland in Fleming Lake. Picture taken on July $26^{\text {th }}, 2019$.

Others have documented the functionality of the FTW to improve water quality. ${ }^{2,7-10}$ FTWs facilitate the growth of macrophytes, and this vegetation growing on the treatment wetland will uptake nutrients. ${ }^{3,7}$ 
The matrix of the FTW and the roots of the vegetation provide growing space for a microbial biofilm consisting of phosphorus and nitrogen fixing bacteria, which accounts for a large portion of nutrient uptake and sequestration. ${ }^{3}$ The phosphorus uptake and release depend on the season and plant life cycle. A small portion of plant-assimilated phosphorus, generally $10-20 \%$, is buried in residual plant material. ${ }^{8}$ Researchers theorize that because macrophyte roots are suspended in the water column, P sorbed to soil particles attaches to biofilms growing on plant roots. ${ }^{9-10}$

For nitrogen, the two largest removal pathways for FTWs are denitrification and assimilation. ${ }^{11}$ Denitrification is the process completed by microorganisms where nitrate is transformed into dinitrogen. The denitrification process involves conversion stages of nitric oxide and nitrous oxide. Microorganisms use nitrate for energy during anaerobic respiration; therefore, denitrification generally occurs in very low oxygen or anaerobic environments. Plants assimilate ammonia and nitrate for growth. Plant residuals that do not decompose and are added to the benthic material are long-term nitrogen stores. ${ }^{8}$

The uptake and sequestration of nutrients by macrophytes and microorganisms are the primary task of FTWs in most contexts. A FTW also acts as a physical filter through the interactions of plant roots with the water, gathering sediment and suspended solids. ${ }^{12}$

Aside from nitrogen and phosphorus concentrations, there are a variety of water quality tests and parameters that are useful for quantitatively evaluating the performance of FTWs. Specific conductance (SC), as a measure of the ability of a substance to conduct electricity, indicates the concentration of cations in water or ionic strength. SC infers the concentration of substances such as dissolved salts, and anions like chlorides that charge balance with calcium and magnesium. Road salt pollution has become more of concern in northern climates. DO is a vital measurement for determining the ability of a body of water to support life, as many aquatic species are unable to survive below a certain threshold of DO in the water. ${ }^{5}$ Hypoxia can occur as a direct consequence of eutrophication. There is limited information available on how FTWs affect $\mathrm{pH}$, but changes in $\mathrm{pH}$ can have significant effects on aquatic ecosystems, such as damage to microbial communities, reductions in phytoplankton and macrophyte diversity, and a decrease in the abundance of sensitive species. ${ }^{14}$ These field measurements analyzed together can reflect the direct influence of nonpoint source pollution when a regional control data set is available. Minnesota as part of the Clean Water Legacy amendment has been collecting statewide $\mathrm{pH}, \mathrm{DO}, \mathrm{SC}$, and nutrient data for decades across different scales.

Prior literature ${ }^{15-16}$ investigated the nutrient removal ability of FTWs in controlled environments through mesocosm studies, but there is an acknowledged shortage of field studies regarding FTW effectiveness once islands are deployed in natural systems, particularly in the context of urban stormwater retention ponds. ${ }^{12,17}$ We did both mesocosm and field studies to better understand the importance of hydrologic scale. We applied environmental monitoring principles to provide a baseline for qualitative and quantitative FTW performance evaluation at a pond and a lake in Minnesota.

This is a novel approach to studying FTWs in the upper Midwestern USA, measuring changes over time in both mesocosms and natural water bodies. This allowed us to establish the difference between treatment groups in controlled mesocosms, and scale up natural systems. ${ }^{18}$ Data was collected over a period of 12 weeks in 2015 at mesocosms, and 13 weeks at two sites where FTWs were in use to control eutrophication and improve water quality in 2019. There are key differences between evaluating FTW performance in a mesocosm versus in a natural environment; in mesocosms, conditions can be precisely controlled, something that is impossible once experiments are scaled up to natural lakes and ponds. In most mesocosm studies of FTWs, the FTW covers a large percentage of the water's surface; frequently ranging from $15-65 \% .{ }^{1}$ However, in the context of actual commercial use in lakes and ponds, FTWs will cover a far smaller percentage of surface area. At the pond study site in Vadnais Heights, Minnesota - FTWs covered $0.57 \%$ of the surface area, and in the lake study site - Fleming lake, Minnesota - FTWs only covered $0.08 \% .{ }^{4}$ The essential question we asked is whether consistent measurements of FTW effectiveness were possible in the context of low coverage rates in uncontrolled environments compared to controlled mesocosms.

In addition to investigating the effectiveness of FTWs in improving water quality, another objective of this work was to qualitatively view FTW durability in a Northern climate. There have been few studies of FTWs conducted in Northern climates. As such, the effect of long winters and repeated freeze-thaw cycles on the performance and survivability of FTWs was largely unknown. One of the objectives in placing FTWs in Fleming Lake was to observe their function over seasons and determine how long they could last with appropriate maintenance. Maintenance involved replanting vegetation with seed or new transplants, and examining wear and tear of the island matrix. Understanding the durability of FTWs in harsh conditions is important to provide guidance on maintenance needs and cost estimates for future projects. Recent research has concluded that repeated freezethaw cycles can have detrimental impacts on FTW structure. ${ }^{19}$ Movement of ice in the winter can also cause damage to the anchoring system used to hold FTWs in place. Furthermore, at the microscopic level, repeated freezing and thawing is a significant factor in the physical degradation of plastics into smaller particles..$^{20}$ However, physical degradation is only one of the pathways by which plastic can break down: thermal oxidation, hydrolysis, and photo-oxidation are also significant. ${ }^{19}$ The degradation rate of plastics varies greatly with environmental conditions; moisture, heat, ultraviolet light, and microbial action are all especially important factors. ${ }^{19}$ Though some research has found no significant amount of microplastics in water from constructed FTWs, the potential release of microplastics from degradation of the matrix remains a concern. ${ }^{21}$ An FTW placed in an outdoor environment is exposed to light, moisture, microbial colonization, and in the case of Northern climates, freezing and ice movement that could cause physical damage. Winter plant survival and predators can also delay full plant community development essential for a fully functional FTW.

\section{Methods}

\section{Mesocosm study}

The experimental design consisted of ten 10,265-liter mesocosm tubs located on the St. Paul campus of the University of Minnesota. Five tubs served as controls (containing only water) and five contained FTWs. The mesocosm tubs were approximately 104 centimeters long, 81 centimeters wide, and 63.5 centimeters deep. FTWs were 33 -centimeter-long by 30.5-centimeter-wide and 16.5 centimeters thick and were centrally anchored in the five treatment tubs. The water surface area covered by the FTWs was approximately $15 \%$. The top half of the FTWs were wrapped in coir to protect against ultraviolet light degradation. A central holding tank collected the experiment water for each experiment batch. The tank was approximately 2.4 meters wide by 2.4 meters long and 0.7 meters deep and could hold a maximum of approximately 4,032 liters. 
Three plant species were planted within each of the five floating treatment wetlands prior to the experiment. Three holes were drilled in each FTW by the manufacturer - Midwest Floating Island. Holes were 11-centimeters-deep and 5-centimeters in diameter. Within the drilled holes, approximately 3.7 centimeters were filled with ground coconut to allow water to infiltrate up through the floating treatment wetland matrix. On top of the ground coconut, approximately 7.3 centimeters of mixed compost soil and peat moss was placed to plant the experiment plants. Peat moss and soil were mixed to a three-part soil to one-part peat moss ratio by weight, per standard FTW practice.

Three plant species were planted within the three pre-drilled holes (one plant per hole) on each FTW: Juncus effuses, Eleocharis acicularis, and Glyceria canadensis. Sprouts of each species were purchased from regional suppliers. Plants were planted within the FTWs 20 days prior to experiment commencement and allowed to grow throughout the summer of 2015 as different batches of spiked water were added weekly for 12 weeks. The use of three different plant species was selected for two reasons. First, FTWs are generally planted with more than one plant species. Second, by comparing three plant families, sedge, rush, and grass, the experiment can identify which plant family may be more efficient in nutrient removal. More design details can be found in Deering (2016).

Water was spiked in the central holding tank and tested for: TP, $\mathrm{PO}_{4}-\mathrm{P}, \mathrm{NO}_{3}-\mathrm{N}$, Ammonia-N, temperature, DO, SC, turbidity, and $\mathrm{pH}$. Then 189 liters of the spiked water was pumped into each mesocosm tub. Seven days later, the physicochemical properties and nutrient concentrations of the water in the tubs was sampled and analyzed in the lab.

The median percent reductions in $\mathrm{PO}_{4}-\mathrm{P}$ and $\mathrm{NO}_{3}-\mathrm{N}$ between experiment and control tubs were analyzed using Wilcoxon rank sum tests because the data were not normally distributed. ${ }^{23}$ The Wilcoxon rank sum test was also employed to determine differences in median concentrations of TP and Ammonia-N. Both nutrients had concentrations below the detection limits (17\% of TP samples and $8 \%$ of Ammonia-N samples); therefore, percent reductions could not be calculated. Differences between experiment and control tubs were tested at the 0.05 significance level. Wilcoxon rank sum tests were used to analyze the difference in physicochemical properties of water because results were not normally distributed. Physicochemical differences between experiment and control tubs were tested at the 0.05 significance level. The assimilation of Phosphorus by the three different plant species were analyzed using the Kruskal-Wallis test. With the small sample size for each species $(n=3)$, normality could not be assumed. The statistical software RStudio was used for all analyses.

\section{Field scale study}

Sites were located in Minnesota where Midwest Floating Island installed FTWs using grant funding, with the goal of improving water quality. Site one, a wet stormwater retention pond in Vadnais Heights, Minnesota, and site two is a small lake called Fleming Lake, in Fleming township, north central Minnesota (Figure 2). The stormwater pond had three $1.5-\mathrm{m} \times 1.5-\mathrm{m}$ FTWs installed, and Fleming Lake had twelve FTWs of similar size, although some islands were linked together to make a larger island surface area. All islands followed design and construction protocols developed by BioHaven ${ }^{\circledR}$ Floating Treatment Wetlands and partially produced at the Midwest Floating Island factory and in situ along the shoreline. The FTWs were installed during the summer of 2016 at both locations. Plants described above were planted into islands and further details about survival and replanting are described in. ${ }^{4}$

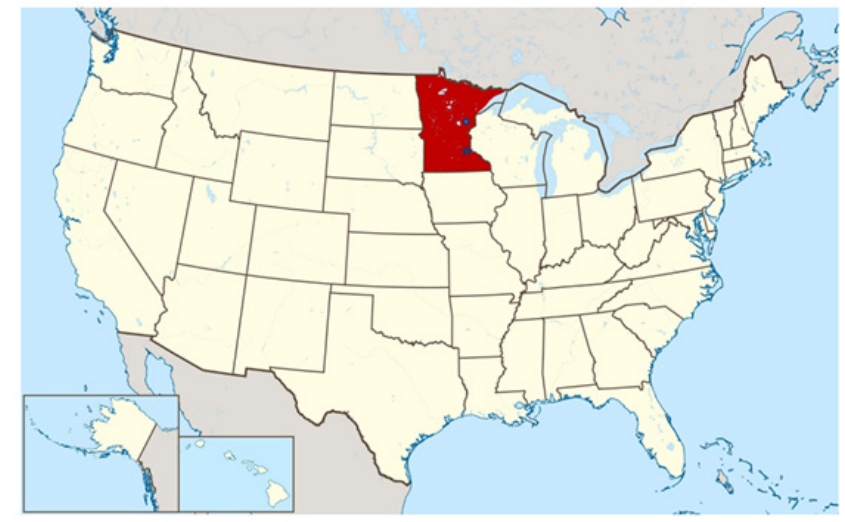

Figure 2 Shows Minnesota located in North America where site one, the Star near the Twin Cities and site two, the diamond located in Northcentral Minnesota.

The Vadnais Heights Pond is located at 45.068048N, 93.093557W latitude and longitude. See Figure 2 which shows a star in Minnesota for site one and a diamond in Northcentral Minnesota for site two - Fleming Lake. The pond has a surface area of $2433-\mathrm{m}^{2}$ and a maximum depth of 0.81-m (Ortega, 2018). The pond falls within the Sucker Lake catchment, which has land cover of $69.83 \%$ developed land, $15.72 \%$ forest, $6.25 \%$ water, and $8.21 \%$ wetland according to the national land cover database. ${ }^{24-25}$ The pond itself has a narrow riparian buffer of trees to the South, and planted wildflowers to the East, but otherwise primarily borders suburban lawn. Due road salt, the pond does not freeze completely during the winter (Figure 3).

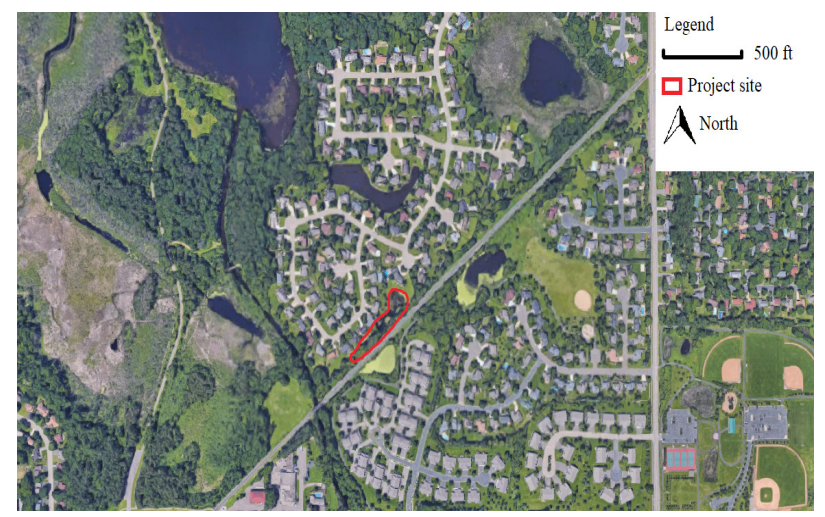

Figure 3 Location of Vadnais Pond and surrounding land use, (from Ortega, 2018). ${ }^{4}$

Fleming Lake is a shallow 297-acre lake (maximum depth 15 $\mathrm{ft}$ ) located in Aitkin County north of the Twin Cities, Minnesota at $46.63 \mathrm{~N}, 93.50 \mathrm{~W}$ latitude and longitude (Figure 4). Land cover in the surrounding catchment (within $300-\mathrm{m}$ of the shoreline) is $62.7 \%$ wetland, $14.8 \%$ perennial grass/hay land, $11.3 \%$ forest, and $10.3 \%$ developed as of 2016 according to data from the Minnesota LakeBrowser and National Land Cover Database. ${ }^{24-25}$ In 2016, it was considered nutrient impaired due to excess nutrient levels and algal eutrophication. ${ }^{26}$ Fleming Lake freezes to a depth of half a meter in the winter, with up to 175 days of ice cover per year. ${ }^{4}$

Specific conductivity ( $\mathrm{SC}$ ), $\mathrm{pH}$, turbidity, $\mathrm{DO}, \mathrm{NO}_{3}$ and $\mathrm{NO}_{3}-\mathrm{N}$, and $\mathrm{PO}_{4}-\mathrm{P}$. These values were measured using three different instruments. A Hach Nitratax ${ }^{\circledR}$ probe for $\mathrm{NO}_{3}$ and $\mathrm{NO}_{3}-\mathrm{N}$ a Hach DR890 colorimeter with PhosVer ${ }^{\circledR}$ reagent for $\mathrm{PO}_{4}-\mathrm{P}$, and a YSI 6820 multiparameter water quality sonde for field measurements. Sampling was focused on the active growth season in Minnesota during July and August. 


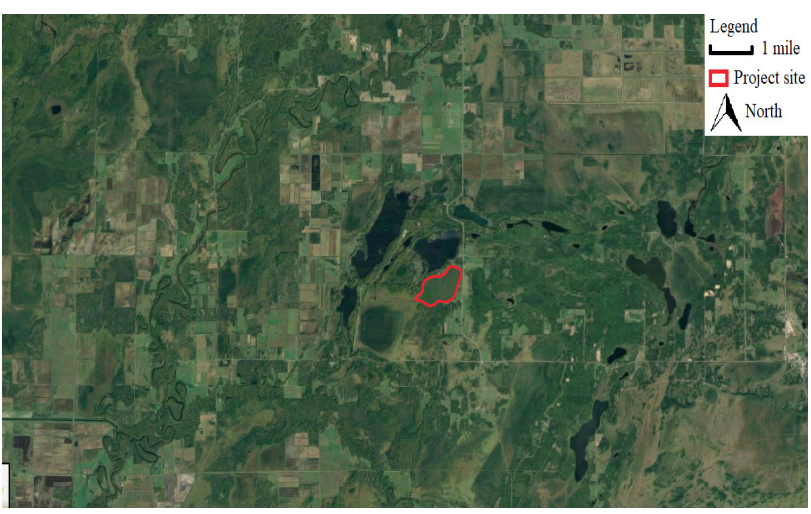

Figure 4 Location of Fleming Lake in north-central Minnesota (From Ortega, 2018). ${ }^{4}$

Baseline samples were taken on June $4^{\text {th }}, 2019$, for the sampling site 1 (Vadnais Pond), and every week after July $3^{\text {rd }}$. No sampling was performed for a period of four weeks between the initial baseline samples and the rest of the study period. Chlorophyll $a$ measurements and other data from the Vadnais Pond were collected and modeled in 2017 by Ortega, (2018). ${ }^{4}$ Unfortunately $\mathrm{PO}_{4}-\mathrm{P}$ could not be measured in 2017 due to equipment failure. All sampling at the Vadnais Pond were performed at the same point on the Northeast shore of the pond. Samples were collected from directly below the surface using a sampling pole attached to a collection bottle and were then transferred to a 1-L Nalgene high-density polyethylene (HDPE) bottle. Samples were then transported back to the lab for analysis. All measurements for the Vadnais Pond were from tests performed in the lab.

Comprehensive water sampling at Fleming Lake was performed twice: once on July $17^{\text {th }} 2019$, and again on August $29^{\text {th }} 2019$. Five sample sites were arrayed at points of interest within the lake; the two inlets, the outlet, the approximate center of the lake or deepest portion, and adjacent to FTWs, see Figure 5). Turbidity data for Fleming Lake as well as land cover data was sourced from the Minnesota LakeBrowser developed by the University of Minnesota's Remote Sensing and Geospatial Analysis Laboratory in collaboration with the Water Resources Center (University of Minnesota, 2018). Measurement of $\mathrm{pH}, \mathrm{SC}$, turbidity, and DO were done on-site using the YSI 6820 sonde. Samples were taken directly below the surface using 1-L HDPE bottles.

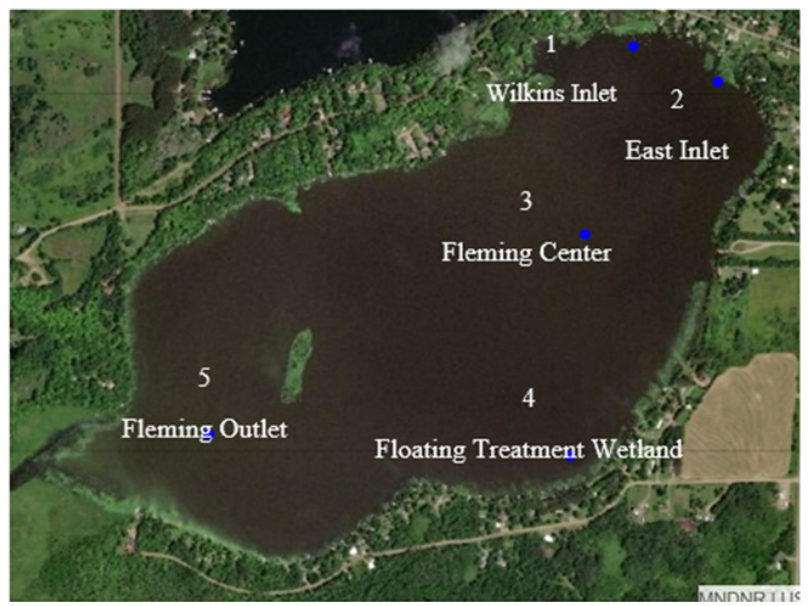

Figure 5 Sampling locations at Fleming Lake, marked by blue points on the map. Image source: (Minnesota Department of Natural Resources, 2018). Sample site numbers correspond to the order in which sites were visited (first through fifth), and the designations in table I of the results section. The location names that correspond to the numerical designations are noted in the figure.
Water samples collected from Fleming Lake were stored in a cooler and refrigerated immediately upon returning to the lab to minimize disruption to the results due to travel time. Analysis of nutrients occurred within allowed holding times. Intensive data collection was supplemented with data collected by a retired engineer living on Fleming Lake on July $1^{\text {st }}$ and July $23^{\text {rd }}, 2019$. The supplemental data was collected from the same sampling points using a Hach $40 \mathrm{~d}$ multiparameter set of probes including, a LDO dissolved oxygen probe and temperature corrected conductivity probe. In addition to the 2019 data collected through monitoring in this project, past data was also used to provide a meaningful comparison over time. Past data was primarily sourced from Ortega (2018). ${ }^{4}$

During lab analysis, four measurements of each parameter were taken, with the first being a test run to check instrument calibration. Each run came from a separate sample. Between sample runs, the bottles were rinsed with deionized water and dried to prevent disruption to the results. The sampling vials used in the colorimeter and the sonde probes were also rinsed between every measurement. For every measurement of samples from the Vadnais Pond after July $3^{\text {rd }}$, the sample was poured through a sieve fitted to the sample bottle before measurement. This was to prevent algae floating in the sample from interfering with measurement of $\mathrm{DO}, \mathrm{PO}_{4}-\mathrm{P}$, turbidity, and $\mathrm{NO}_{3}$ and $\mathrm{NO}_{3}-\mathrm{N}$. To conduct measurements for $\mathrm{SC}, \mathrm{pH}$, turbidity, and $\mathrm{DO}$, the YSI 6820 was immersed in the surface water after checking the calibration. After waiting 1 minute for the measurements to stabilize, the measured value was recorded, and the bottle and probe were rinsed with first tap water, then deionized water. Measurement of $\mathrm{NO}_{3}$ and $\mathrm{NO}_{3}-\mathrm{N}$ followed a similar procedure. The Nitratax probe was immersed in the sample, then took measurements every 15 seconds. The probe was left in the sample until measurements stabilized, then the final value recorded. To measure $\mathrm{PO}_{4}-\mathrm{P}$ concentration, the manufacturer's recommended procedures were followed for the colorimeter. $25 \mathrm{~mL}$ of sample was added to two glass sample cells; one blank, and one to which a pouch of Hach PhosVer reagent was added. The cell with the reagent was shaken for 15 seconds, then left for 2 minutes to allow the reaction to proceed. The colorimeter was calibrated using the blank cell to set a value of $0.0 \mathrm{mg} / \mathrm{L}$, then the cell with the reagent was measured, and the value was recorded.

Calibration of the instruments used in measurement was performed in accordance with the manufacturer's recommendations. The Nitratax probe was calibrated using a two-point calibration prior to the study, and calibration was checked each time the probe was used. The YSI sonde was also calibrated prior to field data collection. The $\mathrm{pH}$ probe of the sonde was calibrated using a 2-point calibration with RICCA standard reference buffer at a $\mathrm{pH}$ of 7.00 and 10.00. The DR890 colorimeter was zeroed each time a measurement was performed, as per the measurement instructions from the manufacturer.

Analysis of the collected data was performed in Microsoft Excel. Data was processed into scatterplots depicting value location over time. Additionally, two statistical tests were performed; a regression to establish the presence of trends over time, and an ANOVA for repeated measures to establish whether there was a statistically significant difference between the initial and final measurements. A threshold of $p<0.05$ was used as the threshold for statistical significance in the ANOVA.

\section{Results}

\section{Mesocosm study}

Median percent reduction of $\mathrm{NO}_{3}-\mathrm{N}$ in experiment tubs and control tubs was $33 \%$. The percent removal was more varied in experiment tubs, with a median absolute deviation of $16 \%$. Control tubs had a 
median absolute deviation of $11 \%$. Differences in percent reduction of $\mathrm{NO}_{3}-\mathrm{N}$ between the control and experiment tubs were found to be statistically insignificant $(p=.5115)$. The null hypothesis was percent reductions were not different; the alternative hypothesis was percent reductions in experiment tubs were higher than in control tubs. Experiment tubs removed a higher percentage of nitrogen than control tubs in batches 7 through 12. Similar to $\mathrm{PO}_{4}-\mathrm{P}$ reduction in batches 1 through 6 , batch 5 was exempt to the trend of control tubs removing more $\mathrm{NO}_{3}-\mathrm{N}$ than experiment tubs. During batch 5, both experiment and control tubs removed $51 \%$ of $\mathrm{NO}_{3}-\mathrm{N}$ (Figure 6). Nitrate-N reduction was not significantly correlated to water temperature, $\mathrm{pH}$, or DO concentrations.

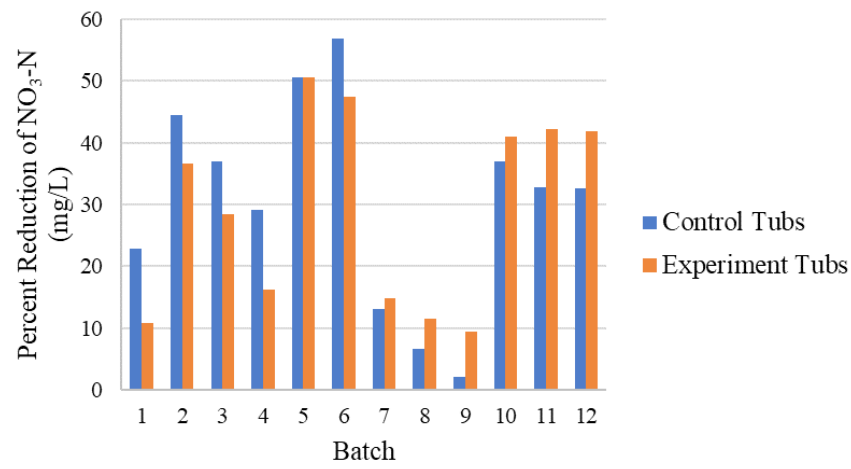

Figure 6 Median reduction efficiency of $\mathrm{NO}_{3}-\mathrm{N}$.

When FTWs removed more $\mathrm{NO}_{3}-\mathrm{N}$ than the control (batches 7 12), the median removal rate was $0.33 \mathrm{~g} / \mathrm{m}^{2} /$ day $\mathrm{NO}_{3}-\mathrm{N}$

Median $\mathrm{PO}_{4}-\mathrm{P}$ reduction and median absolute deviations in experiment tubs were $47 \% \pm 9.8 \%$ and $47 \% \pm 17 \%$ in control tubs. Differences in percent reduction of $\mathrm{PO}_{4}-\mathrm{P}$ between the control and experiment tubs were found to be statistically insignificant at the 0.05 significance level based on a Wilcoxon rank sum test $(p=.6678)$. The null hypothesis was there was no difference in percent reduction of $\mathrm{PO}_{4}-\mathrm{P}$ between the experiment and control; the alternative hypothesis was percent reductions in experiment tubs were higher than in control tubs. Experiment tubs removed more $\mathrm{PO}_{4}-\mathrm{P}$ than control tubs during batches 7 through 12, where starting concentrations were targeted at $0.33 \mathrm{mg} / \mathrm{L} \mathrm{PO}_{4}-\mathrm{P}$. Batch 10 is one exception; control tubs outperformed experiment tub reduction by $1 \%$. During batches 1 through 6, where experiment water was spiked to $0.10 \mathrm{mg} / \mathrm{L}$ $\mathrm{PO}_{4}-\mathrm{P}$, control tubs outperformed experiment tubs. Batch 5 was one exception; experiment tubs outperformed control tubs (Figure 7). $\mathrm{PO}_{4}-\mathrm{P}$ reduction was not significantly correlated to water temperature, $\mathrm{pH}$, or DO concentrations in linear regression analyses.

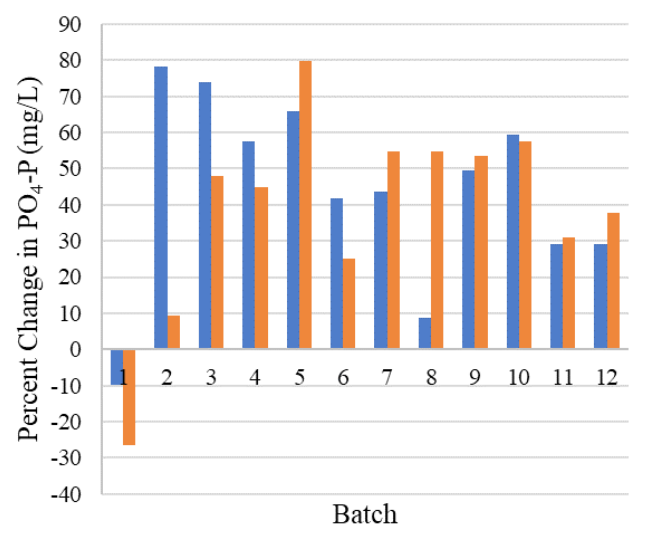

Figure 7 Median reduction efficiency of $\mathrm{PO}_{4}-\mathrm{P}$.
When FTWs generally removed more $\mathrm{PO}-\mathrm{P}$ than the control (batches 7 - 12), the median removal rate was $0.05 \mathrm{~g} / \mathrm{m}^{2} / \mathrm{day} \mathrm{PO}_{4}-\mathrm{P}$.

TP percent removal in experiment tubs was equal to or higher than percent removal in control tubs. The median percent removal in experiment tubs was $51 \% \pm 11 \%$. The median percent removal in control tubs was $37 \% \pm 8 \%$. Since a percent reduction for TP could not be calculated for certain batches, median concentrations were statistically compared using Wilcoxon rank sum tests. Differences in median concentrations for TP were found to be statistically insignificant at the 0.05 significance level $(p=.226)$. TP reduction was not significantly correlated to water temperature or DO. Total phosphorus reduction was correlated to $\mathrm{pH}$ in linear regression analysis $\left(\mathrm{R}^{2}=0.7179\right)$ in experiment tubs; no significant relationship was detected in control tubs. The median removal rate for known TP reductions (batches 4,5 , and 7-12) was $0.05 \mathrm{~g} / \mathrm{m}^{2} /$ day TP. In batches 3 through $6, \mathrm{PO}_{4}-\mathrm{P}$ comprised a median of $58 \%$ of TP. In batches 7 through $12, \mathrm{PO}_{4}-\mathrm{P}$ made up a higher median percentage of TP, $82 \%$.

The average DO percent saturation in experiment tubs was $68.66 \%$ $\pm 20.71 \%$. Experiment tubs never exceeded $100 \%$ DO. Control tubs had a higher average DO percent saturation, $99.99 \% \pm 23.61 \%$. The differences in DO percent saturations were statistically significant ( $p$ $=.00556)$.

The average $\mathrm{pH}$ in experiment tubs was $7.69 \pm 0.362$. The average $\mathrm{pH}$ in control tubs was $8.43 \pm 0.599$. The differences in $\mathrm{pH}$ were statistically significant $(p=.006621)$.

\section{Vadnais pond}

The regression depicted in Figure 8 indicates that from an initial value of approximately $1.5 \mathrm{mg} / \mathrm{L}$ nitrate on June $5^{\text {th }}$, nitrate concentrations declined at a rate of $0.005 \mathrm{mg} / \mathrm{L}$ per day, with an $\mathrm{R}^{2}$ value of 0.5358 . A similar procedure was followed for the $\mathrm{NO}_{3}-\mathrm{N}$ data; a standard linear regression was performed on the mean of all data points collected (however, due to substantial overlap between the data points, only the mean is plotted for NOx-N). The resulting regression showed a marginal decline, with an $\mathrm{R}^{2}$ value for the linear model of 0.3177 . Error depicted for the nitrate data is the standard deviation calculated about the mean. The standard deviation was calculated separately for each set of four measurements for all parameters. The maximum value of the standard deviation occurred on day 77, with a standard deviation of $0.216 \mathrm{mg} / \mathrm{L}$. For the $\mathrm{NO}_{3}-\mathrm{N}$ data, there was sufficient overlap between the measured values that the standard deviation was zero or negligible for all points. An ANOVA for repeated measures was performed on the nitrate measurements, and there was not a statistically significant change in concentration between dates at $p<0.05$. While there was a decline, it did not reach the threshold for significance.

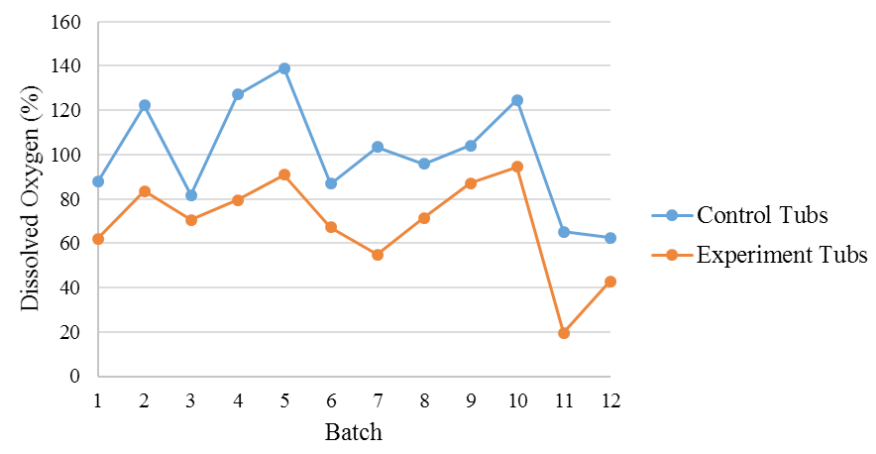

Figure 8 Average DO percent saturation in experiment and control tubs. 
An exponential regression was performed using the means of each set of samples in order to quantify the trends on the graph. The regression equation is shown in Figure 9. Based on the regression equation, $\mathrm{PO}_{4}-\mathrm{P}$ concentrations appeared to display exponential decay over the study period. As with the previous figures, error bars show values within one standard deviation of the mean. The maximum standard deviation was $0.0723 \mathrm{mg} / \mathrm{L}$, on the first day of measurements. A single-factor ANOVA for repeated measures was performed on the data points to establish the statistical significance of the observed trend, and the results show that there was a statistically significant difference over time in $\mathrm{PO}_{4}-\mathrm{P}$ concentration, with $\mathrm{p}=0.002583$.

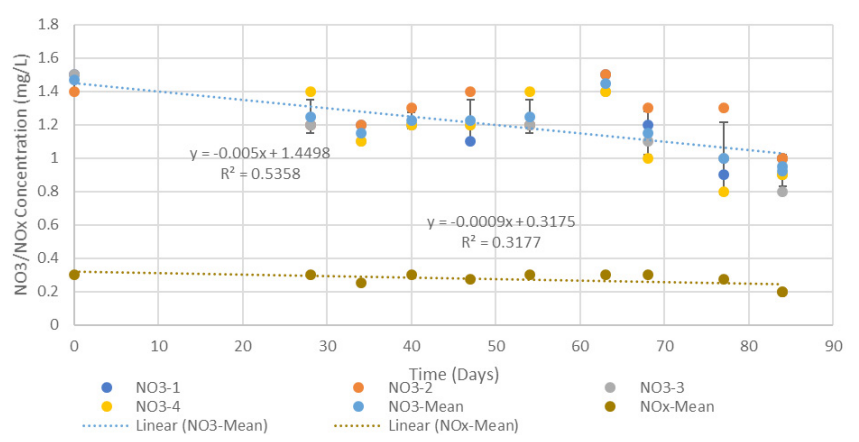

Figure 9 Measurements of nitrate and nitrate-nitrogen over time in milligrams per liter for the Vadnais Heights sample site. For this graph, as with all others on which a regression has been performed, the date on the $\mathrm{x}$-axis was replaced by a count of days since the first sample to facilitate the regression.

A linear regression was performed on the mean $\mathrm{pH}$ measurements collected at the Vadnais Pond site. The results show a clear decline in $\mathrm{pH}$ over the study period, with $\mathrm{pH}$ declining by approximately 0.0053 per day from an initial value of approximately 7.91. The $\mathrm{R}^{2}$ value for the linear model is 0.6191 . Error bars are representative of the standard deviation calculated about the mean. The maximum value of the standard deviation occurred on day 47 , with a value of 0.185 $\mathrm{pH}$ units.

A linear regression was performed on the mean DO concentration over time for the Vadnais Pond site. A measurable decline occurred over the study period, approximated in the linear model as a decline of $0.0177 \mathrm{mg} / \mathrm{L}$ dissolved oxygen per week, with an $\mathrm{R}^{2}$ value of 0.3215 . Although there was a pronounced downward trend, the low $\mathrm{R}^{2}$ value indicates low linearity and substantial variation from one measurement to the next. The error bars in Figure 9, as with previous figures, are the standard deviation calculated about the mean. The maximum standard deviation occurred on day 0 , with a value of $0.5385 \mathrm{mg} / \mathrm{L}$. The reduction in DO from initial to final measurements was statistically significant, as verified by an ANOVA for repeated measurements, which found significance at $\mathrm{p}<0.05$.

A linear regression performed on the data found no conclusive evidence of a trend, with an $\mathrm{R}^{2}$ value of 0.098 indicating a poor linear model fit. In addition, there was no statistically significant change between initial and final measurements. The standard deviation was minimal for all usable measurements except for those on day 47, which had a standard deviation of 0.127 .

Qualitatively, the Vadnais Pond islands remained intact during and beyond the study period. Vegetation grew and filled out the floating island matrix. The matrix showed little to no sign of wear and tear compared to the Fleming Lake islands.

\section{Fleming lake}

With Fleming Lake, we present the data in a table format, mostly because there were only small differences in measured data.

Table 1 illustrates the type and range of data collected at Fleming Lake. See Figure 5 for sampling locations. During the course of the study period, Fleming Lake underwent a substantial increase in algal blooms, particularly towards late August. This is likely due to the dieback of curly-leaf pondweed and other aquatic plants that temporarily increasing available nutrients in the open water column, allowing an algal bloom to occur. Observed changed in water quality parameters coincide with the increasingly eutrophic conditions observed at the end of August. An increase in nutrient concentrations near one of the inlets, and a decrease nearer the outlet, a decrease in DO. In addition, an increase in SC was observed from one of the inlets, indicating an increase in groundwater loading.

Table I Data for water quality metrics and physiochemical properties collected from Fleming Lake during the two comprehensive sampling runs

\begin{tabular}{lllllllllll}
\hline Date & Location & $\begin{array}{l}\text { Temp } \\
\left({ }^{\circ} \mathrm{C}\right)\end{array}$ & $\begin{array}{l}\mathbf{S C} \\
(\mathbf{m} / \mathbf{c m})\end{array}$ & $\mathbf{p H}$ & $\begin{array}{l}\text { Turbidity } \\
(\mathbf{N T U})\end{array}$ & $\begin{array}{l}\text { DO } \\
(\% \text { saturation) }\end{array}$ & $\begin{array}{l}\text { DO } \\
(\mathbf{m g} / \mathbf{L})\end{array}$ & $\begin{array}{l}\text { Nox }-\mathbf{N} \\
(\mathbf{m g} / \mathbf{L})\end{array}$ & $\begin{array}{l}\text { NO3 } \\
(\mathbf{m g} / \mathbf{L})\end{array}$ & $\begin{array}{l}\text { PO4 } \\
(\mathbf{m g} / \mathbf{L})\end{array}$ \\
\hline 17-Jul & 1 & 25.4 & 0.109 & 8.72 & 5.1 & 118.2 & 9.7 & 0.3 & 1.3 & 0.03 \\
17-Jul & 2 & 24.77 & 0.117 & 8.27 & 2.8 & 88 & 7.2 & 0.3 & 1.2 & 0.04 \\
17-Jul & 3 & 25.32 & 0.109 & 8.32 & 4.2 & 11.4 & 9.69 & 0.3 & 1.2 & 0.07 \\
17-Jul & 4 & 25.55 & 0.109 & 8.26 & 2.8 & 96.3 & 9.63 & 0.3 & 1.2 & 0 \\
17-Jul & 5 & 25.62 & 0.109 & 8.54 & 3.7 & 120.1 & 9.81 & 0.3 & 1.2 & 0.15 \\
29-Aug & 1 & 17.91 & 0.111 & 7.64 & 15 & 80.6 & 7.75 & 0.3 & 1.2 & 0.01 \\
29-Aug & 2 & 16.11 & 0.15 & 7.17 & 25 & 57.5 & 5.6 & 0.4 & 1.6 & 0.1 \\
29-Aug & 3 & 17.96 & 0.111 & 7.01 & 12.7 & 95.6 & 9.06 & 0.2 & 1 & 0.04 \\
29-Aug & 4 & 17.9 & 0.11 & 7.62 & 13 & 93.9 & 8.91 & 0.1 & 0.4 & 0.03 \\
29-Aug & 5 & 17.84 & 0.11 & 6.62 & 11.4 & 94.7 & 8.99 & 0.2 & 0.8 & 0.03 \\
\hline
\end{tabular}

The main driver of eutrophication is nutrient loading (nitrogen and phosphorus). ${ }^{6}$ Evaluating the statistical significance of changes in nitrate and phosphate concentration is important to evaluate the severity of the observed eutrophication; Ortega (2018) saw a similar eutrophic trend with Chlorophyll $a .^{4}$ An ANOVA for repeated measures was run for both $\mathrm{NO}_{3}-\mathrm{N}$ and $\mathrm{PO}_{4}-\mathrm{P}$ concentrations and found no statistically significant change in either case. With only two measurements to draw from, this only shows that there was no 
significant change from July to late August because the lake follows a similar pattern every year. It is not that we have no information about what may have happened to nutrient concentrations in between these points. We do know based on past data collection from Ortega (2018) and data collected weekly from a long-term homeowner, and retired engineer, May and June tend to be algal free, but July and August are algal rich months. ${ }^{4}$

DO measurements peaked in midsummer and then declined substantially by the end of August. This trend is consistent with other observed changes in the lake, namely an increase in algae and eutrophic conditions at the end of the summer. An ANOVA for repeated measurements found that the observed changes were statistically significant at $\mathrm{p}<0.05$. The algal blooms and eutrophication reducing available DO is clearly concerning. However, while this effect was present across sample sites, it was most pronounced at the inlets, meaning that water flowing into Fleming Lake was less oxygenated than water flowing out, a positive sign for the health of the lake and its ability to resist further eutrophication. Qualitative observation and photographic records of the lake show intensifying algal blooms in late August, though this did not match the severity of previous years. Changes in SC over time were observed at Fleming Lake, particularly at the East inlet. However, an ANOVA for repeated measures found that the changes were not statistically significant for the lake as a whole.

Six of the eighteen islands installed in Fleming Lake had sustained serious damage over the winter of 2019-2020 and had to be removed. On each of these islands, the vegetation was largely dead (Figure 10), several had visible structural damage (Figure 11), and loss of buoyancy. This loss of buoyancy caused the FTWs to sit slightly below the surface, posing a hazard to watercraft (Figure 10). This necessitated the removal of 6 of the 18 FTWs, which were removed on June $4^{\text {th }}$ and $5^{\text {th }}, 2020$. The islands were towed to a public water access, pulled out of the lake, then sawed into smaller pieces for transport. We qualitatively examined the factors that contributed to the eventual removal of the FTWs from Fleming Lake, drawing from novel observations and existing literature to put forth potential explanations. We noted that geese attacked and ate the plants placed on the islands. In the first spring and summer in 2017 which the FTWs were installed on Fleming Lake, seven islands showed signs of having been attacked by geese, including damaged fencing, damaged plants, and goose fecal matter. ${ }^{4}$ Various control measures have since been put in place to prevent further damage, of which the most successful was a metal fencing over the surface of the FTW. Similar damage was present on the islands in 2020, indicating that predation of the planted vegetation by geese was an ongoing damage issue to the islands.

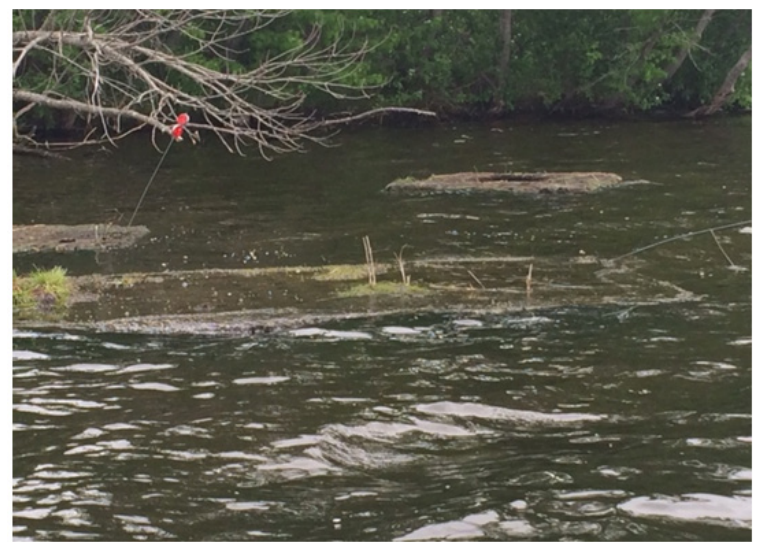

Figure I 0 Floating treatment wetlands partially submerged and stripped of vegetation. Image taken June $4^{\text {th }}, 2020$.

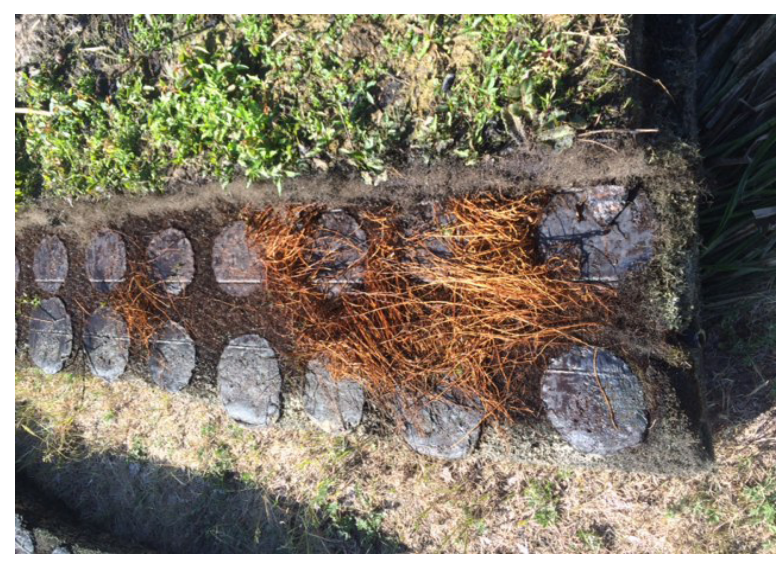

Figure I I FTW from Fleming Lake that was folded over itself during the winter. The movement of ice across the lake surface pulled the FTW, tangling the anchor cables and folding it upon itself.

\section{Discussion}

One method of determining whether the FTWs in this study produced a demonstrable improvement in water quality is whether there was a statistically significant decline in nutrient concentrations. To accurately evaluate whether there was a significant difference, data catchment scale would have provided more understanding about loading in uncontrolled natural systems. But the contact area of FTW to surface water body area appears to be far more important. Mesocosm data clearly showed $\mathrm{PO}_{4}-\mathrm{P}$ reduction at the $15 \%$ coverage in controlled tubs.

Nitrate and $\mathrm{NO}_{3}-\mathrm{N}$ had not previously been evaluated for the areas studied in the context of FTW efficacy. With little data available for comparison, it can only be determined whether there was a significant decline over this study period. An ANOVA for repeated measures was performed on the nitrate measurements, and there was not a statistically significant change in concentration between sampling dates at $p<0.05$. While there was a decline, it did not reach the threshold for significance. This is not necessarily surprising, as it has been found that the optimal area coverage for FTWs to remove nitrogen is around $25 \%{ }^{7}$ which is larger than the $15 \%$ we used in the mesocosm study. With the FTWs in the Vadnais Pond covering only $0.57 \%$ of the total area, any significant impact on nitrogen would likely be localized to the immediate area around and under the FTWs. ${ }^{4}$ In Fleming Lake, nitrate and $\mathrm{NO}_{3}-\mathrm{N}$ remained similar as shown on Table 1 with a slight decrease near the outlet, however, the FTWs likely had no influence on those results.

The overall trend in $\mathrm{PO}_{4}-\mathrm{P}$ concentration for Vadnais Pond was far more apparent than the nitrate data. The relative decline from the initial baseline value to the final measurement was far greater $(0.28 \pm 0.072$ to $0.02 \pm 0.011)$ than nitrate. A single-factor ANOVA for repeated measures was performed on the data points to establish the statistical significance of the observed trend, and the results show that there was a statistically significant difference over time in $\mathrm{PO}_{4}-\mathrm{P}$ concentration, with $\mathrm{p}=0.002583$. Based on the data that was collected, an exponential decay model appears to fit the trend best, though the acquisition of more consistent data points in the first half of summer may have shown a different trend. In Fleming Lake no trend was observed because there were more influencing factors beyond the FTWs controlling phosphorus. Fleming Lake has substantial internal loading - recycling of stored phosphorus in the lakebed.

A reduction in $\mathrm{NO}_{3}-\mathrm{N}$ and $\mathrm{PO}_{4}-\mathrm{P}$ concentration is a positive sign for the health of any surface water body, as lower nutrient loads 
correspond to reduced algal blooms. However, qualitative observation of the Vadnais Pond and Fleming Lake found an increase in algal blooms throughout the summer, peaking in late August. One potential explanation for this phenomenon is that the increase in algae abundance caused a temporary increase in the uptake of nutrients, resulting in a decrease in nutrient concentrations in the water column despite no change in nutrient load. FTWs were likely pulling nutrients, but we were not able to quantify the precise nutrient extraction between the FTWs and algae growing in the surface water.

Typically, in lacustrine systems $\mathrm{pH}$ can change throughout the summer. Nutrients in the water column along bicarbonate can influence the movement of hydrogen. The $\mathrm{pH}$ results were not driven by FTW activity but normal biological production that occurs in most northern lake systems. ${ }^{4}$ Nevertheless, one potential cause of $\mathrm{pH}$ decline may have come from precipitation. Rainwater has a lower $\mathrm{pH}$ than the typical lake or pond, ranging from 4.5 to 5.6 depending on regional conditions, so it is possible that large volumes of precipitation could have this effect. ${ }^{27}$ The summer of 2019 had the most precipitation since 1892 for parts of Minnesota, lending credence to the hypothesis that heavy rains were a significant factor in the decline in $\mathrm{pH} .{ }^{28} \mathrm{~A}$ extreme $\mathrm{pH}$ reduction in surface water can have substantial harmful effects; biodiversity at all trophic levels would be reduced upon acidification. $^{14}$

DO measurements over time also showed a clear downward trend with more algal productivity. This was expected, as increasing algal blooms over the course of the summer intensified eutrophication available oxygen in the water declines. This decline was statistically significant, as verified by an ANOVA for repeated measurements, which found significance at $p<0.05$. FTWs are often implemented in an effort to reduce eutrophication and by extent improve available DO. Prior literature indicates that FTWs can have mixed effects; it has been observed that directly underneath FTWs, lower DO conditions may occur. ${ }^{17}$

It must be noted that while statistically significant changes in some parameters were observed, fully understanding the cause and effect will require more rigorous data collection of systems with $>1 \%$ areal coverage. With the FTWs covering only $0.57 \%$ of the available surface area in the Vadnais Pond and $0.08 \%$ of Fleming Lake, the most significant impacts on water quality were expected to be small and localized. Some studies of FTWs have suggested that they could be highly effective at treating stormwater in retention ponds by filtering sediment, sequestering nutrients, and controlling algal blooms..$^{12,29}$ Periphyton production appears to be the key ingredient for optimal pollutant sequestration. ${ }^{4}$ The results of this study suggest that in order for FTWs to function as intended in these contexts, they must have substantially greater surface area coverage than at the sites evaluated in this study. We cannot conclude whether $15 \%$ is the optimal level of coverage, but based on the mesocosm data, there is a probability that measurable reductions could occur. In addition, it has been noted that to truly remove excess nutrients from the system over time, the plants grown on a FTW should be harvested on a regular basis. ${ }^{29}$

A key objective of 2020 data collection was to identify potential causes of the deterioration of the FTWs placed in Fleming Lake by synthesizing qualitative observation with prior studies of the same site $^{4}$ and other studies of FTWs in the literature. Prior research has noted that colonization by aquatic organisms can affect the buoyancy of microplastics. This phenomenon, typically referred to as 'biofouling', can also sink larger plastic objects when colonization by macro-organisms occurs and develops a thick mat. ${ }^{30}$ The FTW goal was to cultivate periphyton and aquatic macrophytes for the purposes of removing nutrient pollution. Nevertheless, they may be susceptible to biofouling induced buoyancy loss. If the anchors holding an island in place are tangled by a strong lake fetch blowing an island to the point where it becomes waterlogged, the FTW may not be able to support plants (Figures 10, and 11). In experimental investigations of the impact of biofouling on buoyancy, it was found that the size and shape of matrix material was an important factor in the surface longevity of matrix material..$^{31}$ Midwest Floating Island has addressed this issue and issues related to biodegradation from sunlight.

\section{Experimental flaws and sources of error}

Observations of natural systems, unlike studies in controlled mesocosms, are fundamentally inconsistent because all variables cannot be controlled. The observed decline in nutrient concentration over the study period corroborated with an improvement in other water quality metrics from previous years suggesting that the FTWs deployed may have indeed produced measurable improvement in water quality. However, the essential issue with this study is that it cannot be known how much of the observed changes are due to the FTWs versus changes in the environment (i.e., precipitation, temperature, or land use). For example, eutrophic lakes and bodies of water tend to show seasonal variations in nutrient loading patterns. In the particular with $\mathrm{PO}_{4}-\mathrm{P}$, the tendency is for nutrient loading to peak over the summer. ${ }^{32-33}$ There was great variation in patterns between bodies of water based on local and regional factors. Having a paired control or using a before and after control impact method would have improved the study design. Nevertheless, we were able to reach back to Ortega (2018) to interpret historical data which showed similar response. ${ }^{4}$ Additional parameters would have been useful, but funding budgets often decide what can be measured. Chlorophyll $a$ concentration as a measurement of algae and aquatic plant activity, and alkalinity to evaluate resistance to $\mathrm{pH}$ changes, since statistically significant changes in $\mathrm{pH}$ were observed in this study.

We acknowledge there were several sources of error in the measurements via instrumentation user errors. But the largest uncontrollable variable was the weather - temperature changes, wind and new water additions are beyond control in a field data collection portion of this study. Precipitation leads to runoff, which increases turbidity, suspended solids, and nutrient loads, all of which may have impacted measurements taken within a short timeframe after rainstorm events.

\section{Conclusion}

In light of the consequences of global climate change, applying knowledge of the natural world to devise new methods of pollution control may be an important task for environmental and ecological engineers and scientists. Many climate models predict an increase in precipitation across temperate regions, with increased runoff and therefore nutrient pollution. ${ }^{7,34}$ FTWs could be one potential method of mitigating this significant issue if small stormwater pond scales are fitted with $>15 \%$ FTWs.

If FTWs are to be utilized as a BMP for water quality improvement, it is necessary to understand the optimal conditions for their use. The results of this study show that at very low surface area coverage, it is difficult to measure statistically significant changes in water quality directly attributable to FTWs. Even at low coverages, FTWs may offer other benefits, such as habitat for native plant and animal species or aesthetic appeal. However, in order to produce measurable, significant improvements in water quality, it is important to position FTWs in locations where they can be deployed at optimal coverage 
rates (optimal being approximately $>15 \%$ coverage for most efficient nitrogen uptake according to Marimon et. al, 2013). ${ }^{7}$ For northern lakes, this is likely impossible because the FTW would create recreational water hazards.

Based on the observations made at Fleming Lake, northern lakes are not a good environment for FTWs to operate in, due primarily to repeated freeze-thaw cycles accelerating degradation (Figure 11), and the movement of ice causing physical damage and shifting of anchors with wind. While FTWs are capable of sustaining plant regeneration after the winter, the sustained period of inactivity also reduces their capacity to take up nutrients. There are potential measures and design changes that can be undertaken to mitigate some of the drawbacks of FTWs that were observed at Fleming Lake. Sturdy fencing was effective at deterring geese. ${ }^{4}$ Either a high vertical fence (height) around the perimeter of the FTW or a netting that covers the surface of the FTW may be effective at preventing geese from attacking vegetation. Can constructed FTWs improve water quality in a northern climate? In stormwater ponds with high pollutant loads and areal coverage $>15 \%$ - we believe the answer is yes!

\section{References}

1. Deering E. Floating Treatment Wetlands in a Northern Climate: Examination of Phosphorus and Nitrogen Removal. University of Minnesota. 2016. p. 1-88.

2. Floating Island International - Natural Clean Water Solutions [WWW Document]. 2021.

3. Zhang CB, Liu WL, Pan XC, et al. Comparison of effects of plant and biofilm bacterial community parameters on removal performances of pollutants in floating island systems. Ecol Eng. 2014;73:58-63.

4. Ortega K. Floating Treatment Wetlands: Inter-Relationships between Engineered Solutions for Nutrient Pollution and their Bodies of Water, dissertation. University of Minnesota. 2018.

5. Díaz RJ, Rosenberg R. Introduction to environmental and economic consequences of hypoxia. Int J Water Resour Dev. 2011;27:71-82.

6. Wurtsbaugh WA, Paerl HW, Dodds WK. Nutrients, eutrophication and harmful algal blooms along the freshwater to marine continuum. Wiley Interdiscip. Rev Water. 2019;6(5);1-27.

7. Marimon ZA, Xuan Z, Chang N. et al. System dynamics modeling with sensitivity analysis for floating treatment wetlands in a stormwater wet pond. Ecol Modell. 2013;267:66-79.

8. Kadlec RH, Wallace SD. Treatment Wetlands. ( $2^{\text {nd }}$ edn). Boca Raton, FL: CRC Press. 2009.

9. Borne KE, Fassman EA, Tanner CC. Floating treatment wetland retrofit to improve stormwater pond performance for suspended solids, copper and zinc. Ecological Engineering. 2013;54:173-182.

10. Tanner CC, Headley TR. Components of floating emergent macrophyte treatment wetlands influencing removal of stormwater pollutants. Ecological Engineering. 2011;37(3):474-486.

11. Lynch J, Fox LJ, Owen JS, Sample DJ. Evaluation of commercial floating treatment wetland technologies for nutrient remediation of stormwater. Ecological Engineering. 2015;75:61-69.

12. Moiseenko TI. Effects of acidification on aquatic ecosystems. Russ J Ecol. 2005;36:93-102.

13. Jones TG, Willis N, Gough R. An experimental use of floating treatment wetlands (FTWs) to reduce phytoplankton growth in freshwaters. Ecol Eng. 2017.
14. Liu J, Wang F, Liu W, et al. Nutrient removal by up-scaling a hybrid floating treatment bed (HFTB) using plant and periphyton: From laboratory tank to polluted river. Elsevier Ltd. 2016;207:142-149.

15. Nichols P, Lucke T, Drapper D, et al. Performance evaluation of a floating treatment wetland in an urban catchment. Water (Switzerland). 2016;8.

16. Wang CY, Sample DJ, Day SD, et al. Floating wetlands for urban stormwater treatment. 2013. p. 1-166.

17. Garcia Chance LM, Van Brunt SC, Majsztrik JC, et al. Short- and longterm dynamics of nutrient removal in floating treatment wetlands. Water Res. 2019;159:153-163.

18. Gupta V, Courtemanche J, Gunn J, et al. Shallow floating treatment wetland capable of sulfate reduction in acid mine drainage impacted waters in a northern climate. J Environ Manage. 2020;263:110351.

19. Klein S, Dimzon IK, Eubeler J, et al. Analysis, Occurrence, and Degradation of Microplastics in the Aqueous Environment. 2017;51-67.

20. Chamas A, Moon H, Zheng J, et al. Degradation Rates of Plastics in the Environment. ACS Sustain. Chem Eng. 2020;8:3494-3511.

21. Ziajahromi S, Drapper D, Hornbuckle A, et al. Microplastic pollution in a stormwater floating treatment wetland: Detection of tyre particles in sediment. Sci Total Environ. 2020;713:136356.

22. Gibbons JD, Chakraborti S. Nonparametric Statistcal Inference. In: N Balakrishnan et al., editors. (5 ${ }^{\text {th }}$ ed.). CRC Press. 2019.

23. Minnesota Department of Natural Resources Climate of Minnesota Minnesota DNR. 2017.

24. University of Minnesota. Minnesota LakeBrowser. 2018.

25. Holst L, US Environmental Protection Agency. US EPA's decision document on Minnesota's 2016 and 2018 Impaired Waters Lists. 2019.

26. Charlson RJ, Rodhe H. Factors controlling the acidity of natural rainwater. Nature. 1982;295:683-685.

27. Minnesota Department of Natural Resources. Climate of Minnesota: Minnesota DNR. 2020.

28. McAndrew B, Ahn C, Spooner J. Nitrogen and sediment capture of a floating treatment wetland on an urban stormwater retention pond-The case of the rain project. Sustain. 2016;8.

29. Kaiser D, Kowalski N, Waniek JJ. Effects of biofouling on the sinking behavior of microplastics. Environmental Research Letters. 2017;12(12).

30. Fazey F, Ryan PG. Debris size and buoyancy influence the dispersal distance of stranded litter. Marine pollution bulletin. 2016;110(1):371377.

31. Jeppesen E, Søndergaard M, Jensen JP, et al. Lake responses to reduced nutrient loading - An analysis of contemporary long-term data from 35 case studies. Freshw Biol. 2005;50:1747-1771.

32. Søndergaard M, Bjerring R, Jeppesen E. Persistent internal phosphorus loading during summer in shallow eutrophic lakes. Hydrobiologia. 2009;710:95-107.

33. Solomon S, Qin D, Manning M, et al. AR4 Climate Change 2007: The Physical Science Basis. Climate change. 2001.

34. Dillon PJ, Rigler F. The phosphorus-chlorophyll relationship in lakes. Limnol Oceanogr. 1994;19:1-10.

35. McAndrew B, Ahn C. Developing an ecosystem model of a floating wetland for water quality improvement on a stormwater pond. $J$ Environ Manage. 2012;202:198-207. 